\title{
Rapidly progressed neuroendocrine carcinoma in the extrahepatic bile duct: a case report and review of the literature
}

\author{
Mariko Kamiya ${ }^{1 *}$ (D, Naoto Yamamoto ${ }^{1}$, Yuto Kamioka ${ }^{1}$, Hirohide Inoue ${ }^{1}$, Hirokazu Yotsumoto ${ }^{1}$, Masaaki Murakawa ${ }^{1}$, \\ Toru Aoyama ${ }^{2}$, Kota Washimi ${ }^{3}$, Kae Kawachi ${ }^{3}$, Takashi Oshima ${ }^{4}$, Makoto Ueno ${ }^{5}$, Norio Yukawa ${ }^{2}$, Yasushi Rino ${ }^{2}$, \\ Munetaka Masuda ${ }^{2}$ and Soichiro Morinaga' ${ }^{1}$
}

\begin{abstract}
Background: Neuroendocrine carcinoma (NEC) originating from the extrahepatic bile duct (EHBD) is very rare but is known for its aggressiveness and poor prognosis. We herein report a case of rapidly progressed NEC in the extrahepatic bile duct.

Case presentation: An 84-year-old man was referred to our facility with obstructive jaundice and abdominal pain. Imaging studies revealed an irregular filling defect in the middle bile duct by endoscopic retrograde cholangiopancreatography and an enhanced wall thickening from the middle to distal portion by enhanced computed tomography. The patient was initially diagnosed with extrahepatic cholangiocarcinoma by a bile duct biopsy and underwent pancreatoduodenectomy with lymph node dissection. The pathological findings showed an NEC with an adenosquamous carcinoma component in the extrahepatic bile duct with lymph node metastases. The patient experienced multiple liver metastases 1 month after surgery and died 3 months after surgery. Due to the rapid progression of his disease, his general condition deteriorated, and he was unable to receive any additional treatments, such as chemotherapy.
\end{abstract}

Conclusion: As shown in our case, NEC of the EHBD has an extremely poor prognosis and can sometimes progress rapidly. Multimodality treatment should be considered, even in cases of locoregional disease.

Keywords: Neuroendocrine carcinoma, Extrahepatic bile duct, Adenosquamous carcinoma

\section{Background}

Neuroendocrine neoplasms (NENs) can arise in various organs through the body, but those arising in the gastrointestinal tract and the pancreas are relatively rare, accounting for $1-1.5 \%$ of all gastroenteropancreatic (GEP) neoplasms [1]. The annual age-adjusted incidence of GEP NENs in the USA was 3.56 per 100,000 persons in 2012, which is rare but steadily increasing [2]. The most common primary site of digestive system was the small intestine (1.05 per 100,000 persons), followed by the

\footnotetext{
* Correspondence: m.kamiya@kcch.jp

${ }^{1}$ Department of Hepatobiliary and Pancreatic Surgery, Kanagawa Cancer

Center, 1-1-2 Nakao, Asahi-Ku, Yokohama 241-8515, Japan

Full list of author information is available at the end of the article
}

rectum (1.04 per 100,000 persons) and the pancreas (0.84 per 100,000 persons) [2]. Only $0.32 \%$ of NENs occur in the extrahepatic bile duct (EHBD), and almost all of them are well-differentiated neuroendocrine tumors (NETs) [3]. Poorly differentiated neuroendocrine carcinomas (NECs) of the EHBD are rare, reportedly accounting for only $0.19 \%$ of EHBD malignancies [4].

GEP NECs are an invasive and progressive disease for which the prognosis is extremely poor due to early widespread metastases [5, 6]. In the WHO 2019 classification, NENs of digestive system are classified into NETs and NECs according to their clinical and molecular differences [7]. The lesions previously classified as NET G3 (NEC) in the 2010 WHO classification were divided into 
NET G3 (well-differentiated high-grade tumor) and NEC (poorly differentiated high-grade tumor) in the 2019 classification system. Well-differentiated NETs have mutations in MEN1, DAXX, and ATRX. NECs are usually associated with TP53 or RB1 mutations, but NET G3 is not. These molecular differences underlie why progression from NETs to NECs does not generally occur and explain the differing clinical behavior of these two categories [7]. Based on the genomic data, the classification of mixed adenoneuroendocrine carcinomas (MANECs) was shifted to the conceptual category of "mixed neuroendocrine non-neuroendocrine neoplasms (MiNENs)" in the 2017 WHO classification system [7, 8]. These mixed neoplasms of digestive system are thought to have a common precursor, such as cancer stem cells that can differentiate into various cell lines [9].

EHBD NEC is also known for being difficult to diagnose preoperatively [3]. Many reported cases were resected with a diagnosis of cholangiocarcinoma and then diagnosed as NEC after surgery. We herein report a rare case of NEC in the EHBD that rapidly progressed after curative surgery and provide a brief review of the literature to further our understanding of this extremely rare and lethal malignancy.

\section{Case presentation}

An 84-year-old man was referred to our hospital for the evaluation of obstructive jaundice and abdominal pain. He had no relevant medical history. On a physical examination, the patient presented with mild jaundice, itching of the skin, and mild discomfort in the upper abdomen. Laboratory tests revealed an elevated level of hepatobiliary enzyme and C-reactive protein $(1.1 \mathrm{mg} / \mathrm{dL})$. The serum level of carcinoembryonic antigen (CEA) was abnormally elevated $(31.8 \mathrm{ng} / \mathrm{mL})$, and the carbohydrate antigen 19-9 (CA19-9) level was within the normal range $(8.2 \mathrm{U} / \mathrm{mL})$. Enhanced computed tomography (CT) showed enhanced wall thickening from the middle to the distal portion of the common bile duct and no enlarged regional lymph nodes (Fig. 1). Endoscopic retrograde cholangiopancreatography (ERCP) demonstrated mild dilatation of the EHBD and an irregular filling defect in the middle bile duct (Fig. 2). Endoscopic ultrasonography revealed irregular wall thickening in the middle bile duct. A plastic stent tube was placed in the EHBD to reduce obstructive jaundice. We diagnosed him with extrahepatic cholangiocarcinoma because carcinoma was detected by a bile duct biopsy.

Pancreatoduodenectomy with lymph node dissection was performed. Heart failure and pancreatic fistula within Clavien-Dindo grade 3 occurred during the postoperative course, but those complications were improved after a few days, and he was discharged on postoperative day 23. One month after the surgery, the serum level of

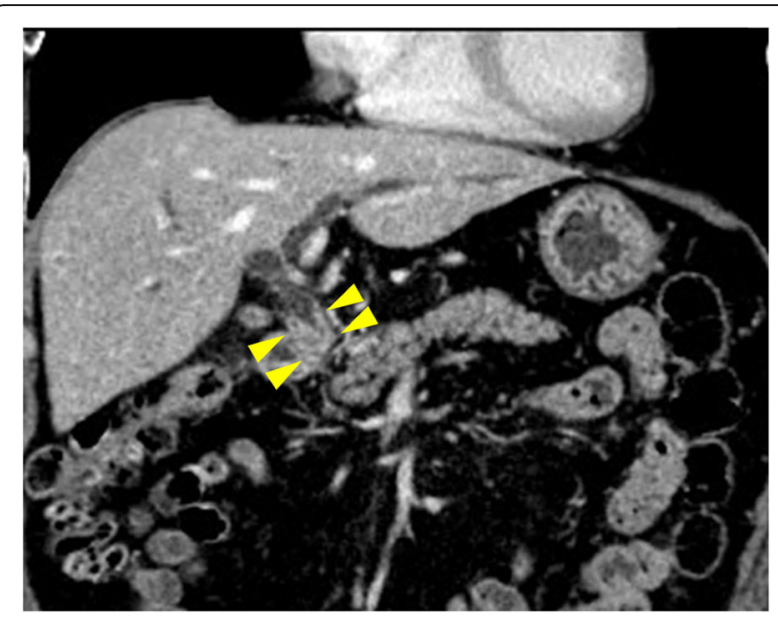

Fig. 1 Enhanced wall thickening from the middle to the distal portion of the common bile duct (arrow) without any enlarged regional lymph nodes was detected by enhanced $C T$ (coronal section image)

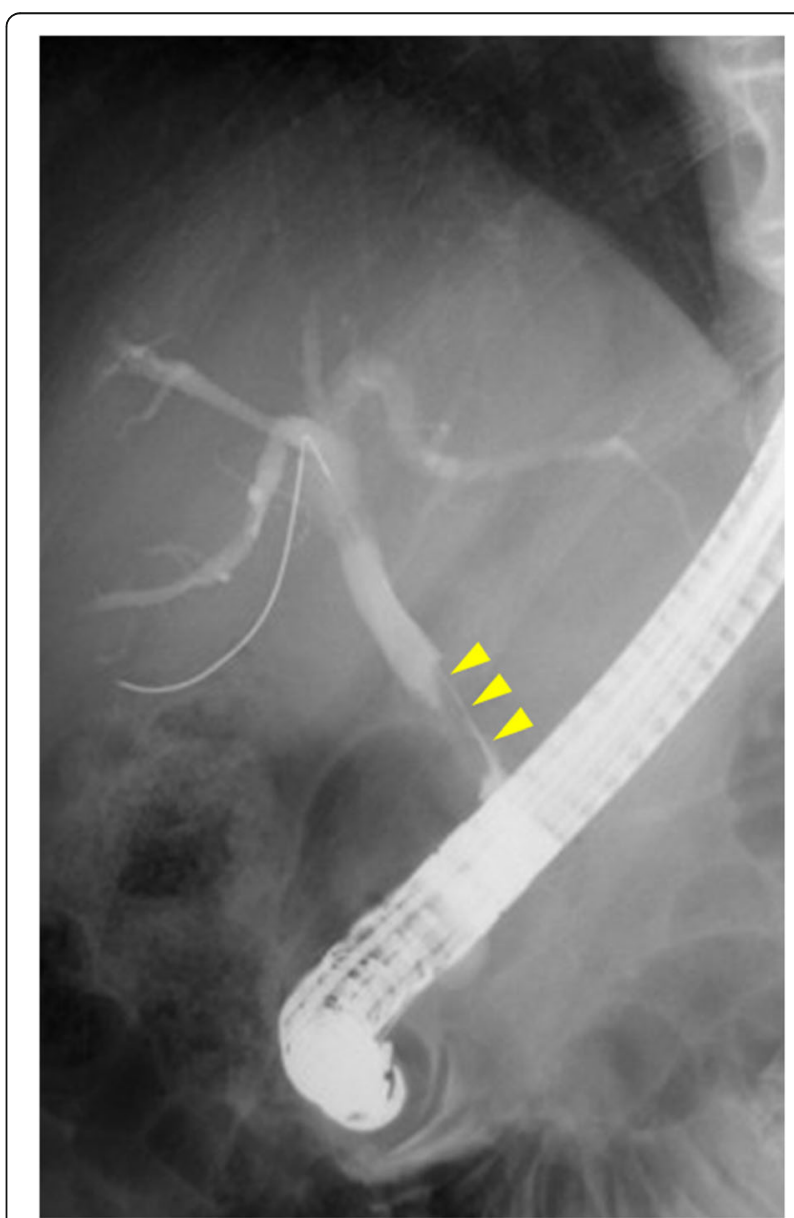

Fig. 2 Endoscopic retrograde cholangiopancreatography revealed mild dilatation of the intra- and extrahepatic bile duct and an irregular filling defect in the middle portion of the common bile duct (arrow) 
CEA was markedly elevated $(306.4 \mathrm{ng} / \mathrm{mL})$, and multiple liver metastases were detected by CT (Fig. 3). Due to the rapid progression of the disease, his general condition deteriorated, and he was unable to receive any additional treatments except for best supportive care. He deceased 3 months after the surgery.

\section{Pathological findings}

Macroscopically, the tumor was circumferentially a flat infiltrating lesion, measuring $25 \times 23 \times 10 \mathrm{~mm}$ located in the middle bile duct around the junction of the cystic duct (Fig. 4). Microscopically, the tumor cells were dysplastic cells with a high nucleo-cytoplasmic ratio (N/C ratio) and had granular hyperchromatic irregular-shaped nuclei. The tumor grew invasively, forming follicular nests and sheets (Fig. 5b). On immunostaining, the tumor cells were positive for synaptophysin, chromogranin A, and CD 56. The Ki-67 labeling index was over $80 \%$. NEC was indicated based on these findings. In addition, the tumor partly showed adenocarcinoma (Fig. 5c) and squamous cell carcinoma areas (Fig. 5d). An adenocarcinoma region was found on the surface of the mucosa, extending and infiltrating into the cystic duct (Fig. 5a). The NEC region was mainly observed below the submucosal layer (Fig. 5a). The NEC component occupied over $80 \%$ of the tumor. Based on these findings, a pathological diagnosis of NEC with adenosquamous carcinoma components was established. Two regional lymph node metastases with NEC were detected (Bd-p, pT2, ly1, v3, ne2, pN1, M0, pStage IIB, UICC8th).

\section{Discussion}

We reported an extremely rare case of NEC in the EHBD that was initially diagnosed as EHBD cancer by a bile duct biopsy and treated with curative resection but showed a rapid disease course after surgery and a poor

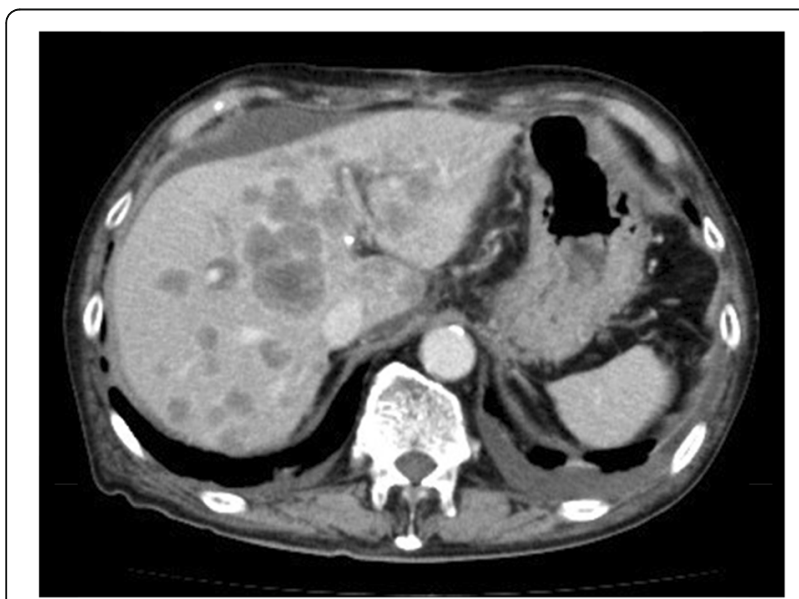

Fig. 3 Multiple liver metastases and ascites on the liver surface were observed by CT (axial section image) 1 month after surgery

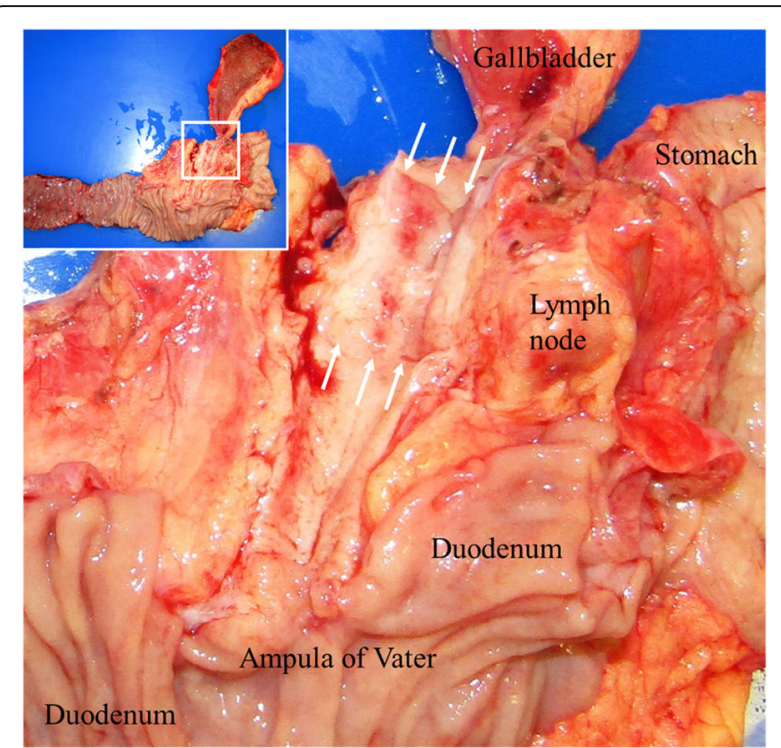

Fig. 4 Macroscopic findings of the resected specimen showed a circumferentially flat, infiltrating lesion in the middle portion of the common bile duct around the junction of the cystic duct (arrow), measuring $25 \times 23 \times 10 \mathrm{~mm}$ in size

prognosis. The optimum treatment for EHBD NEC has not been established due to its rarity. A detailed literary analysis of the clinical features of EHBD NECs may help improve the treatment of this lesion.

We searched the PubMed database using the terms "neuroendocrine carcinoma," "bile duct," "endocrine carcinoma," and "mixed adeno-neuroendocrine carcinoma." Excluding NECs in the intrahepatic bile duct, gallbladder, and ampulla of Vater, only 24 resected cases of primary EHBD NECs were found [3, 10-32]. We briefly summarized these clinical and pathological features (Tables 1 and 2).

Among the 25 resected cases of EHBD NEC (including our case), the median age of the patients was 70.0 years old (range 28-84). Most patients were male, with a male to female ratio of 20:5. Most of patients showed primary symptoms of obstructive jaundice (22 cases), followed by abdominal pain (6 cases), weight loss (3 cases), and nausea ( 3 cases), similar to EHBD cancer. The tumor was located in the perihilar bile duct in 9 cases and in the distal bile duct in 16 cases. The serum levels of CEA and CA 19-9 were abnormally elevated in some cases, regardless of the presence of adenocarcinoma component, but these are not specific tumor markers for biliary NECs. The median Ki-67 index was $71.4 \%$ (range $20-$ $90 \%, n=19$ ). Pancreatoduodenectomy was performed in 12 cases, EHBD resection in 9 cases, and hemihepatectomy with EHBD resection in 4 cases. Lymph node metastases were detected in 12 of 20 cases (Table 2).

It is very difficult to make a diagnosis of NEC preoperatively. The clinical and imaging findings of EHBD 


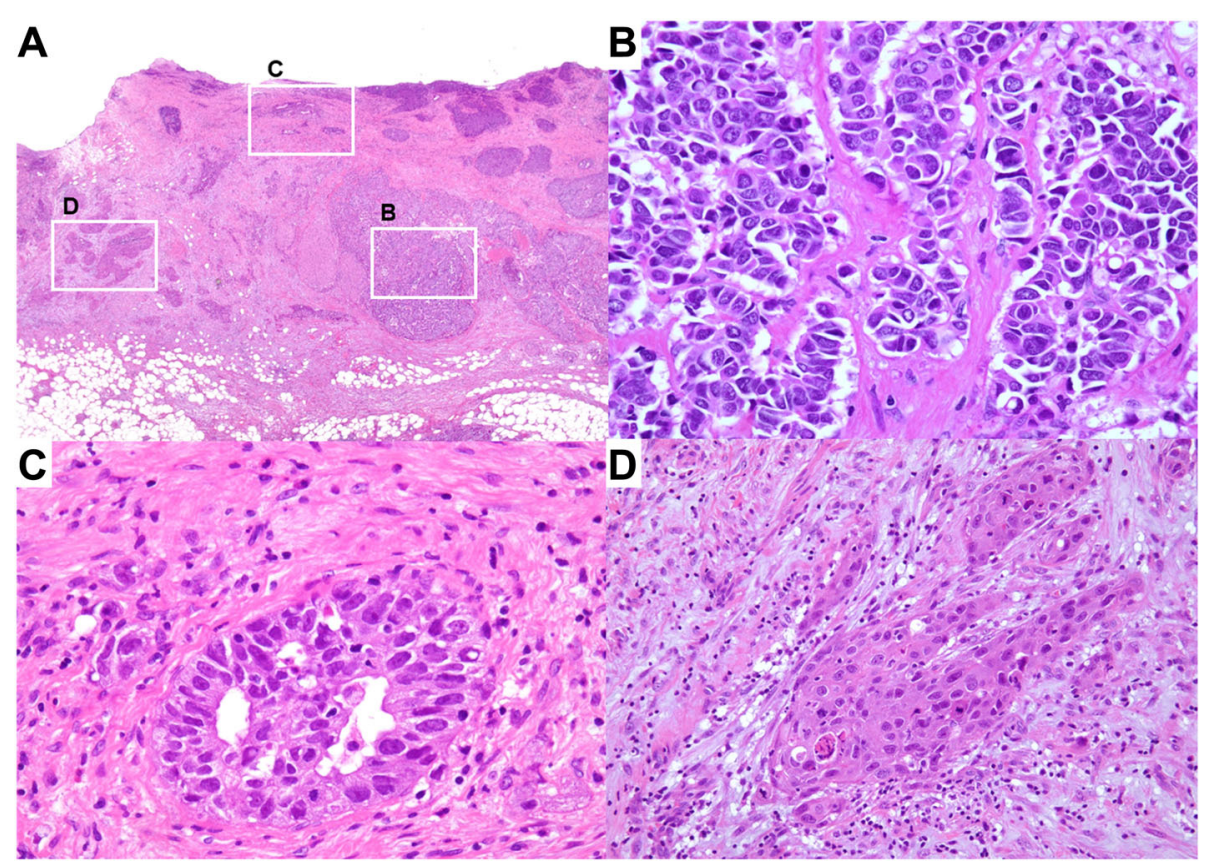

Fig. 5 Microscopic findings of the resected specimen with Hematoxylin-Eosin (HE) staining. a An NEC lesion was observed below the submucosal layer (b). An adenocarcinoma lesion was detected in the surface layer (c). The tumor partly showed squamous cell carcinoma (d). b NEC cells were dysplastic cells with a high N/C ratio and granular hyperchromatic irregular-shaped nuclei. c Adenocarcinoma lesion. $\mathbf{d}$ Squamous cell carcinoma lesion

NEC are very similar to that of EHBD cancer, so a histological examination is required for a definitive diagnosis. A bile duct biopsy was performed in 10 cases, only 3 of whom were diagnosed with NEC before resection [11, $15,23]$. Adenocarcinoma was detected in four cases, and atypical cells or no malignant cells were detected in three cases. Brushing cytology was performed in 11 cases, but NEC could not be detected in any of these cases (adenocarcinoma in 4 cases, atypical cells or no malignant cells in 7 cases). Consequently, 20 patients underwent surgery with a diagnosis of EHBD cancer. The preoperative diagnosis was not mentioned in two cases (Table 2).

One reason for the difficulty associated with making a preoperative pathological diagnosis is that a relatively high proportion of NEC cases have an adenocarcinoma component (52\%, 13 of 25 cases), and this adenocarcinoma component in the superficial layer conceals the NEC component existing in a deeper layer. Approximately $35 \%$ of biliary NENs are MiNENs, and many cases often contain non-neuroendocrine components, as in our case, even if they do not meet the definition of MiNEN (both neuroendocrine and non-neuroendocrine components exceed 30\%) [8]. According to Sasatomi et al., in cases of bile duct NEC with an adenocarcinoma component, the adenocarcinoma lesion is often found in the mucosal to submucosal layer, whereas the NEC lesion is found below the submucosal layer or in an even deeper layer [18]. Therefore, in some cases, cytology or a biopsy cannot detect the NEC component, making a preoperative diagnosis difficult.

Another possible reason is that cytology specimens stained with Papanicolaou and biopsy specimens stained with Hematoxylin-Eosin (HE) alone may have a high false negative rate for diagnosing NEC [3]. Immunohistochemical staining is usually required for a definitive diagnosis of NEC, but pathologists do not always conduct this unless NEC is suspected. In our case, the patient was diagnosed with bile duct cancer based on $\mathrm{HE}$ staining alone preoperatively, and NEC was diagnosed postoperatively.

The prognosis of EHBD NECs is very poor, even in cases of lesions that are clinically localized and surgically resected. The median overall survival was 12 months (95\% confidence interval, 5-20 months) in the 21 cases with follow-up data (Fig. 6). There was no significant difference in the overall survival between patients with and without an adenocarcinoma component in the present study, although the overall survival of biliary MiNEN is reported to be slightly better than that of pure NEC in some literature. However, advanced MiNEN generally shows a relatively poor prognosis that is equal to that of pure NEC [8]. Only 2 patients were reported to survive for more than 2 years. One case was pStage I (T1N0M0) with a tumor size of $30 \mathrm{~mm}$ and remained alive for 36 months, while the other case was pStage IIB (T3N1M0) 


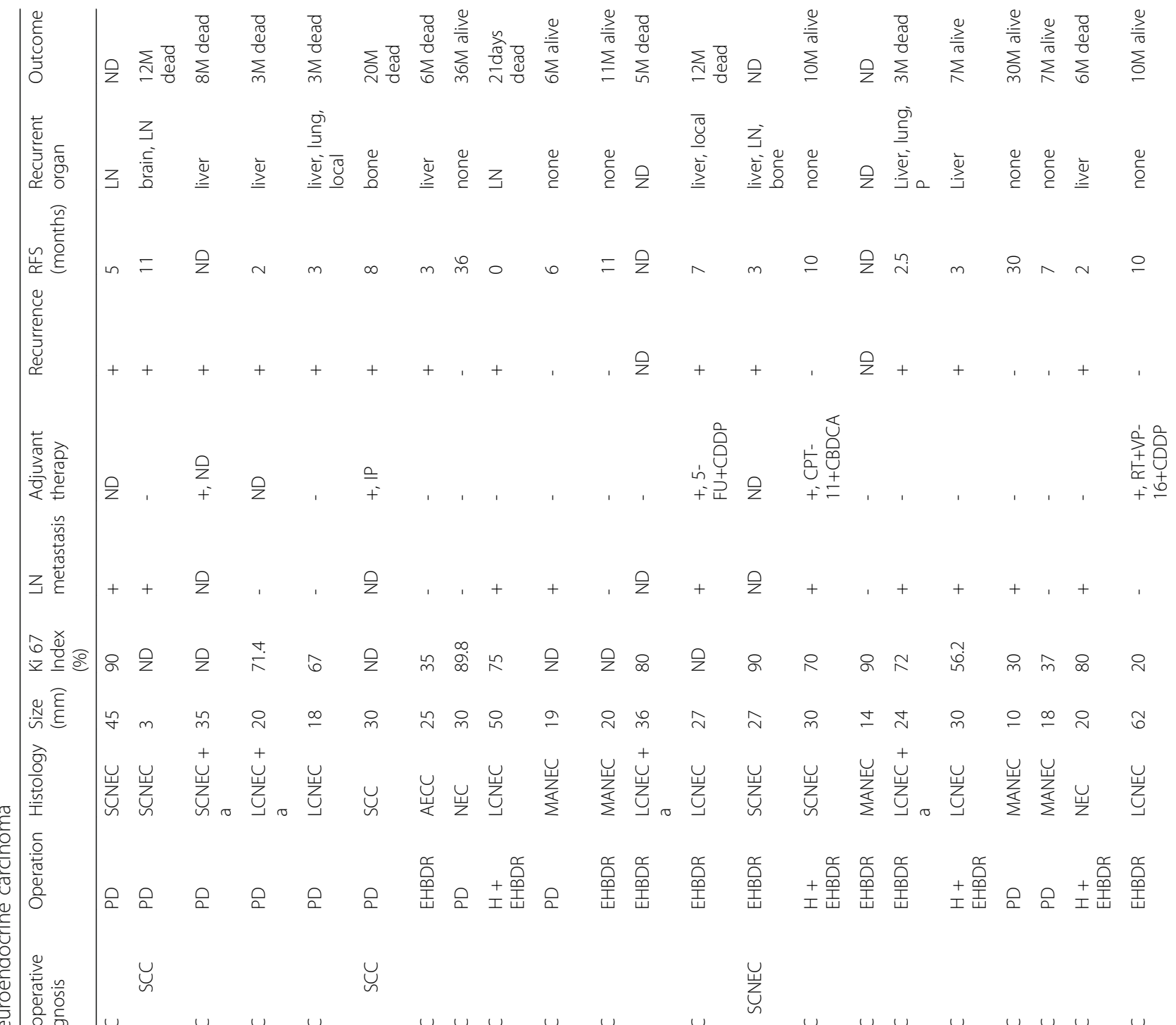

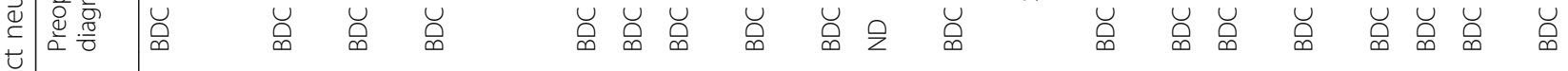

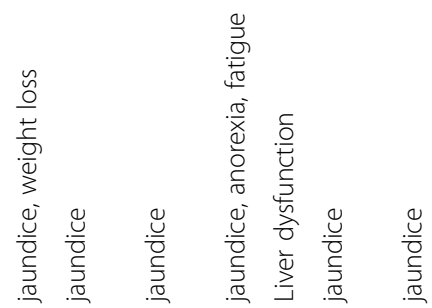

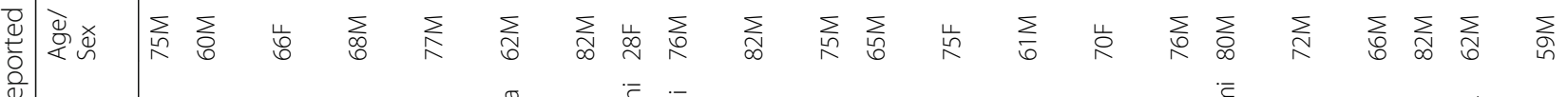

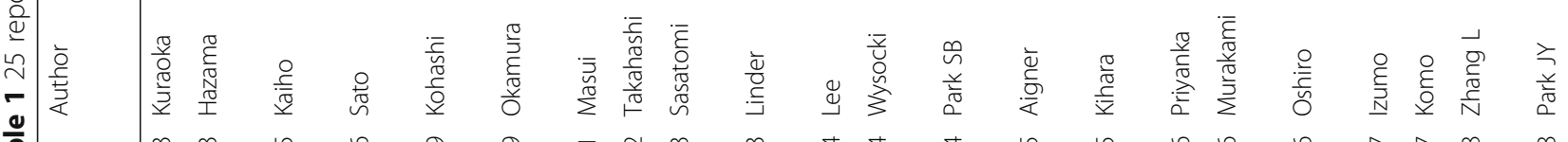
党 


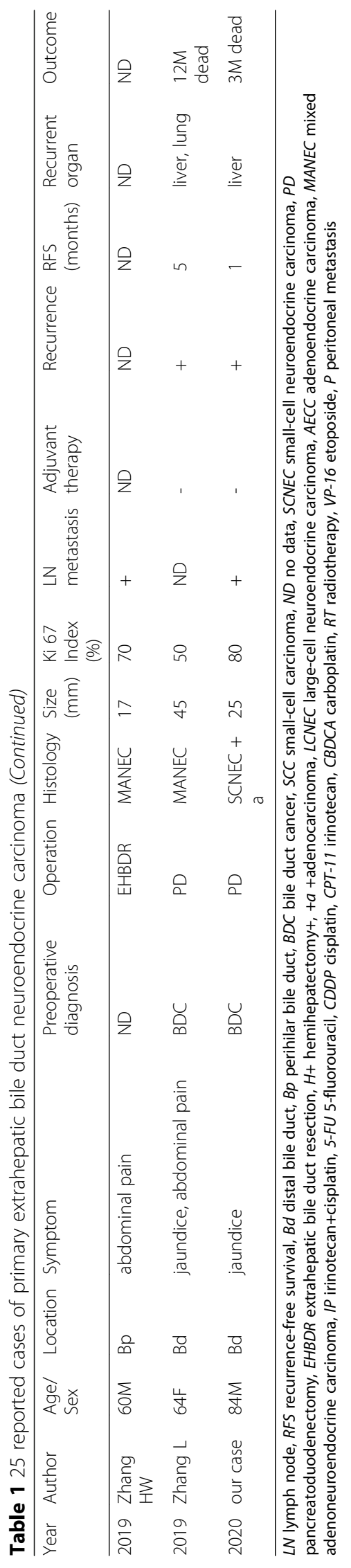


Table 2 Summary of 25 reported cases of primary extrahepatic bile duct neuroendocrine carcinoma

\begin{tabular}{|c|c|c|c|c|}
\hline \multirow[t]{2}{*}{$\operatorname{Sex}(n=25)$} & Male & 20 & Operation $(n=25)$ & \\
\hline & Female & 5 & Pancreatoduodenectomy & 12 \\
\hline Age $(n=25)$ & \multicolumn{2}{|l|}{$\begin{array}{l}\text { median } 70 \text { years (range } \\
\text { 28-84) }\end{array}$} & Bile duct resection & 9 \\
\hline \multirow[t]{4}{*}{ Symptom } & Jaundice & 22 & With hepatectomy & 4 \\
\hline & Abdominal pain & 6 & $\begin{array}{l}\text { Lymph node metastasis } \\
(n=20)\end{array}$ & \\
\hline & Weight loss & 3 & Positive & 12 \\
\hline & Nausea, Vomiting & 3 & Negative & 8 \\
\hline \multicolumn{3}{|c|}{ Preoperative diagnosis $(n=25)$} & $\begin{array}{l}\text { Adjuvant chemotherapy } \\
(n=20)\end{array}$ & \\
\hline & Bile duct cancer & 20 & Yes & 5 \\
\hline & $\begin{array}{l}\text { Neuroendocrine } \\
\text { carcinoma }\end{array}$ & 3 & No & 15 \\
\hline & Not mentioned & 2 & $\begin{array}{l}\text { Neoadjuvant } \\
\text { chemotherapy }\end{array}$ & 3 \\
\hline \multirow{2}{*}{$\begin{array}{l}\text { Location } \\
(n=25)\end{array}$} & $\mathrm{Bd}$ & 16 & Recurrent organ $(n=15)$ & \\
\hline & $\mathrm{Bp}$ & 9 & Liver & 11 \\
\hline Size $(n=25)$ & \multicolumn{2}{|l|}{$\begin{array}{l}\text { median } 25 \mathrm{~mm} \text { (range } 3- \\
62 \text { ) }\end{array}$} & Lymph node & 4 \\
\hline \multicolumn{3}{|c|}{ Ki-67 index $(n=19)$} & Lung & 3 \\
\hline & \multicolumn{2}{|l|}{$\begin{array}{l}\text { median } 71.4 \% \text { (range } \\
\text { 20-90) }\end{array}$} & Local / Bone & 2 \\
\hline
\end{tabular}

with a tumor size of $10 \mathrm{~mm}$ and remained alive for 30 months. No recurrence was observed in either case without any adjuvant therapies. Postoperative recurrence occurred in 15 cases, and the most common recurrent organ was the liver $(n=11)$, followed by the lymph nodes $(n=4)$, and the lung $(n=3)$.

For the treatment of GEP NENs, resection is recommended for well-differentiated NETs (including NET G3) that can be radically resected. However, the role of surgery for GEP NECs is limited, as GEP NEC has a rapid disease course with a poor prognosis that can relapse early after resection, even in cases of clinically localized tumors. Generally, the combination of systemic chemotherapy (neoadjuvant or adjuvant) and local treatment consisting of surgery and radiotherapy should be considered for localized GEP NEC [5]. GEP NECs are chemotherapy-responsive neoplasms, and platinumbased chemotherapy represents the backbone of treatment for both early and advanced-stage GEP-NEC [6].

In the literature, adjuvant chemotherapy, mostly based on regimens for small-cell lung carcinoma (SCLC), was performed in only 5 cases $(n=21)$. Due to the rapid disease course after surgery, a certain number of patients with resected EHBD NEC were unable to receive adjuvant chemotherapy, which was the same as in our case. Notably, the three cases diagnosed with NEC preoperatively all received neoadjuvant chemotherapy with IP (irinotecan + cisplatin) or EP (etoposide + cisplatin) [11,

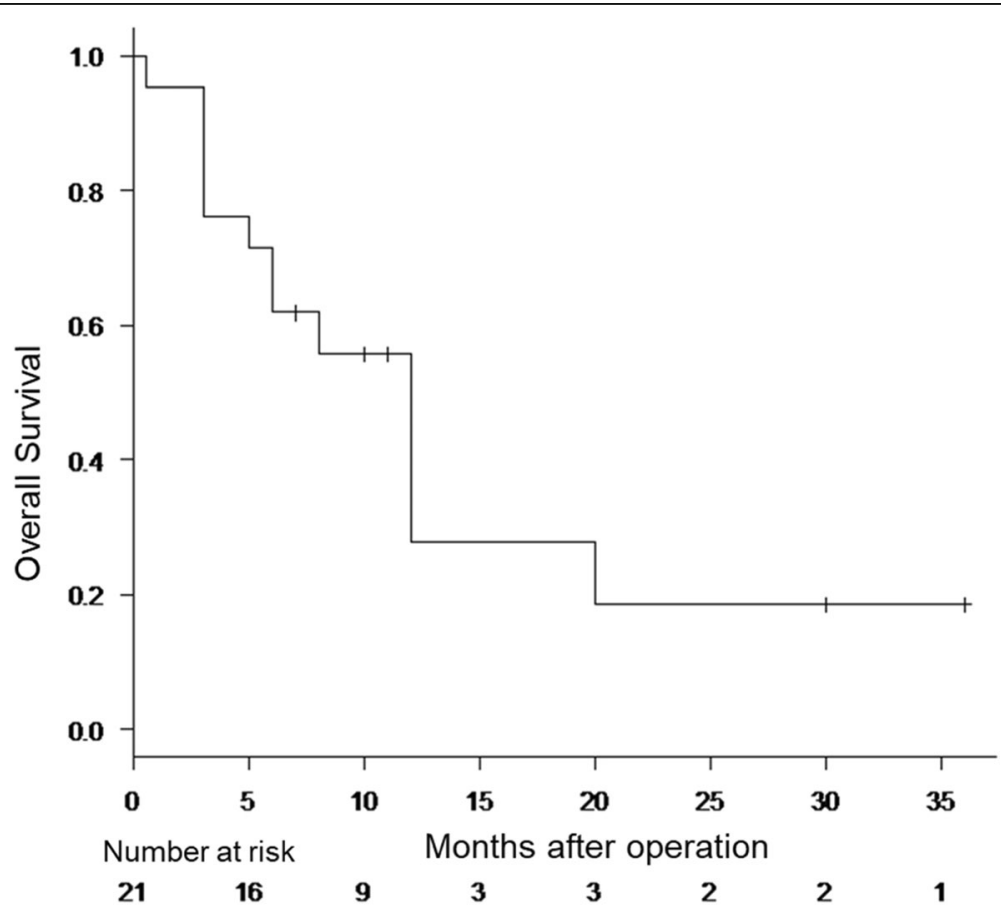

Fig. 6 Survival curves of the 21 resected cases of EHBD NEC. The median OS was 12 months ( $95 \%$ Cl, 5-20 months), and the 1-year survival rate was $27.9 \%$ 
15, 23]. Hazama et al. reported a case of unresectable EHBD NEC due to para-aortic lymph node metastasis that was resected after four cycles of EP. A partial response was obtained, and the residual tumor was only 3 $\mathrm{mm}$ in size with a single lymph node showing one tiny metastasis [11].

Neoadjuvant chemotherapy has some advantages over adjuvant chemotherapy [15, 33]. Many NEC patients already have occult metastases at the time of their diagnosis, resulting in early recurrence and progression after surgery. Neoadjuvant chemotherapy with a platinumbased regimen can control these occult metastases due to its relatively good tumor sensitivity [6,34]. Furthermore, before surgery, patients can maintain good activities of daily living and a good general condition, which allows for more aggressive treatment to be administered. From this perspective, neoadjuvant treatment might be preferred to adjuvant treatment for patients with EHBD NEC, even cases with clinically localized and surgically resectable lesions.

\section{Conclusion}

In summary, we reported a case of resected EHBD NEC with a rapid disease course and poor prognosis. The preoperative diagnosis of primary EHBD NEC is very difficult, and this lesion has an extremely poor prognosis and can progress rapidly after surgery. Multimodality treatment including chemotherapy (neoadjuvant rather than adjuvant), radiotherapy, and surgery should be carefully considered to prolong the survival of patients with EHBD NEC.

\begin{abstract}
Abbreviations
NEN: Neuroendocrine neoplasm; GEP: Gastroenteropancreatic; EHBD: Extrahepatic bile duct; NET: Neuroendocrine tumor; NEC: Neuroendocrine carcinoma; MiNEN: Mixed neuroendocrine nonneuroendocrine neoplasm; CT: Computed tomography; ERCP: Endoscopic retrograde cholangiopancreatography; SCLC: Small-cell lung carcinoma; IP: Irinotecan + cisplatin; EP: Etoposide + cisplatin
\end{abstract}

\section{Acknowledgements}

Not applicable.

\section{Authors' contributions}

MK reported the case and wrote the manuscript. MK, NY, YK, HI, HY, MaM, and SM performed surgery and managed the perioperative course of the patient. KW and KK performed the histological examination. All authors participated in the design of the study. SM revised the manuscript and approved the final version of the manuscript. All authors read and approved the final manuscript.

\section{Funding}

None.

\section{Availability of data and materials}

The dataset supporting the conclusions of this article is included within the article and its additional files.

\section{Ethics approval and consent to participate}

The case report was presented in accordance with the Declaration of Helsinki, and written informed consent was obtained from the patient to publish this case report.

\section{Consent for publication}

We obtained written informed consent from the patient to publish this case report.

\section{Competing interests}

The authors have no competing interests to declare.

\section{Author details}

${ }^{1}$ Department of Hepatobiliary and Pancreatic Surgery, Kanagawa Cancer Center, 1-1-2 Nakao, Asahi-Ku, Yokohama 241-8515, Japan. ²Department of Surgery, Yokohama City University, Yokohama, Japan. ${ }^{3}$ Department of Pathology, Kanagawa Cancer Center, Yokohama, Japan. ${ }^{4}$ Department of Gastrointestinal Surgery, Kanagawa Cancer Center, Yokohama, Japan. ${ }^{5}$ Department of Gastroenterology, Hepatobiliary and Pancreatic Medical Oncology Division, Kanagawa Cancer Center, Yokohama, Japan.

Received: 12 June 2020 Accepted: 15 July 2020

Published online: 03 August 2020

\section{References}

1. Lepage C, Bouvier AM, Faivre J. Endocrine tumours: epidemiology of malignant digestive neuroendocrine tumours. Eur J Endocrinol. 2013;168(4): R77-83.

2. Dasari A, Shen C, Halperin D, Zhao B, Zhou S, Xu Y, et al. Trends in the incidence, prevalence, and survival outcomes in patients with neuroendocrine tumors in the United States. JAMA Oncol. 2017:3(10):133542.

3. Zhang L, Wan D, Bao L, Chen Q, Xie H, Xu S, et al. Neuroendocrine carcinoma in the extrahepatic biliary tract: a case report and literature review. Medicine. 2018;97(29):e11487.

4. Albores-Saavedra J, Batich K, Hossain S, Henson DE, Schwartz AM. Carcinoid tumors and small-cell carcinomas of the gallbladder and extrahepatic bile ducts: a comparative study based on 221 cases from the Surveillance, Epidemiology, and End Results Program. Ann Diagn Pathol. 2009;13(6):37883.

5. Garcia-Carbonero R, Sorbye H, Baudin E, Raymond E, Wiedenmann B, Niederle B, et al. ENETS consensus guidelines for high-grade gastroenteropancreatic neuroendocrine tumors and neuroendocrine carcinomas. Neuroendocrinology. 2016;103(2):186-94.

6. Sorbye H, Strosberg J, Baudin E, Klimstra DS, Yao JC. Gastroenteropancreatic high-grade neuroendocrine carcinoma. Cancer. 2014;120(18):2814-23.

7. Nagtegaal ID, Odze RD, Klimstra D, Paradis V, Rugge $M$, Schirmacher $P$, et al. The 2019 WHO classification of tumours of the digestive system. Histopathology. 2020;76(2):182-8.

8. de Mestier L, Cros J, Neuzillet C, Hentic O, Egal A, Muller N, et al. Digestive system mixed neuroendocrine-non-neuroendocrine neoplasms. Neuroendocrinology. 2017:105(4):412-25.

9. La Rosa S, Sessa F, Uccella S. Mixed neuroendocrine-nonneuroendocrine neoplasms (MiNENs): unifying the concept of a heterogeneous group of neoplasms. Endocr Pathol. 2016;27(4):284-311.

10. Kuraoka K, Taniyama K, Fujitaka T, Nakatsuka H, Nakayama H, Yasui W. Small cell carcinoma of the extrahepatic bile duct: case report and immunohistochemical analysis. Pathol Int. 2003;53(12):887-91.

11. Hazama K, Suzuki Y, Takahashi M, Takahashi Y, Yoshioka T, Takano S, et al. Primary small cell carcinoma of the common bile duct, in which surgical treatment was performed after neoadjuvant chemotherapy: report of a case. Surg Today. 2003;33(11):870-2.

12. Kaiho T, Tanaka T, Tsuchiya S, Yanagisawa S, Takeuchi O, Miura M, et al. A case of small cell carcinoma of the common bile duct. Hepatogastroenterology. 2005;52(62):363-7.

13. Sato $K$, Waseda R, Tatsuzawa $Y$, Fujinaga $H$, Wakabayashi $T$, Ueda $Y$, et al. Composite large cell neuroendocrine carcinoma and adenocarcinoma of the common bile duct. J Clin Pathol. 2006:59(1):105-7.

14. Kohashi T, Matsugu Y, Nakahara H, Ohmori I, Egi H, Urushihara T, et al. Large-cell neuroendocrine carcinoma of the distal bile duct. Clinical journal of gastroenterology. 2009;2(4):291-5. 
15. Okamura Y, Maeda A, Matsunaga K, Kanemoto H, Boku N, Furukawa H, et al. Small-cell carcinoma in the common bile duct treated with multidisciplinary management. J Hepatobiliary Pancreat Surg. 2009;16(4):575-8.

16. Masui T, Doi R, Kawaguchi Y, Iwanaga $Y$, Ito T, Koizumi M, et al. Adenoendocrine cell carcinoma of the extrahepatic bile duct: a case report and review of the literature. Clinical journal of gastroenterology. 2011;4(3): 174-8.

17. Takahashi K, Sasaki R, Oshiro Y, Fukunaga K, Oda T, Ohkohchi N. Welldifferentiated endocrine carcinoma originating from the bile duct in association with a congenital choledochal cyst. Int Surg. 2012;97(4):315-20.

18. Sasatomi E, Nalesnik MA, Marsh JW. Neuroendocrine carcinoma of the extrahepatic bile duct: case report and literature review. World J Gastroenterol. 2013;19(28):4616-23.

19. Linder R, Dorfman T, Ben-Ishay O, Kakiashvili E, Velodavsky E, Kluger Y. Mixed neuroendocrine tumor of the common bile duct. JOP : Journal of the pancreas. 2013;14(1):71-3.

20. Lee SW, Lee IS, Cho YK, Park JM, Kim SW, Choi MG, et al. A case of mixed adenoneuroendocrine carcinoma of the common bile duct: initially diagnosed as cholangiocarcinoma. Korean journal of pathology. 2014;48(6): 445-8.

21. Wysocki J, Agarwal R, Bratton L, Nguyen J, Weidenhaft MC, Shores N, et al. Mixed large cell neuroendocrine carcinoma and adenocarcinoma with spindle cell and clear cell features in the extrahepatic bile duct. Case reports in pathology. 2014:2014:347949.

22. Park SB, Moon SB, Ryu YJ, Hong J, Kim YH, Chae GB, et al. Primary large cell neuroendocrine carcinoma in the common bile duct: first Asian case report. World J Gastroenterol. 2014;20(47):18048-52.

23. Aigner B, Kornprat P, Schollnast H, Kasparek AK, Mischinger HJ, Haybaeck J. A case of focal small-cell neuroendocrine carcinoma in the vicinity of the extrahepatic bile duct, adjacent to an extensive biliary intraepithelial neoplasm: a diagnostic challenge with major clinical implications. Anticancer Res. 2015;35(9):4821-8.

24. Kihara Y, Yokomizo H, Urata T, Nagamine M, Hirata T. A case report of primary neuroendocrine carcinoma of the perihilar bile duct. BMC Surg. 2015;15:125

25. Priyanka Akhilesh S, Kamal Sunder Y, Chandralekha T, Samir P, Prasad KW. Common hepatic duct mixed adenoneuroendocrine carcinoma masquerading as cholangiocarcinoma. Case Rep Gastrointest Med. 2016; 2016:4827050.

26. Murakami M, Katayama K, Kato S, Fujimoto D, Morikawa M, Koneri K, et al. Large-cell neuroendocrine carcinoma of the common bile duct: a case report and a review of literature. Surgical case reports. 2016;2(1):141.

27. Oshiro Y, Gen R, Hashimoto S, Oda T, Sato T, Ohkohchi N. Neuroendocrine carcinoma of the extrahepatic bile duct: a case report. World J Gastroenterol. 2016;22(30):6960-4.

28. Izumo W, Higuchi R, Yazawa T, Uemura S, Matsunaga Y, Shiihara M, et al. A long-term recurrence-free survival of a patient with the mixed adenoneuroendocrine bile duct carcinoma: a case report and review of the literature. Int J Surg Case Rep. 2017;39:43-50.

29. Komo T, Kohashi T, Nakashima A, Ohmori I, Hihara J, Mukaida H, et al. Mixed adenoneuroendocrine carcinoma of the distal bile duct: a case report. Int Surg Case Rep. 2017;39:203-7.

30. Park JY, Jeon TJ. Large cell neuroendocrine carcinoma of the extrahepatic bile duct. The Korean journal of gastroenterology $=$. Taehan Sohwagi Hakhoe chi. 2018;72(6):318-21.

31. Zhang HW, Kou K, Qi J, Xie EB, Wang M, Li Y, et al. Mixed adenoneuroendocrine carcinoma of the extrahepatic bile duct: a case report. J Int Med Res. 2019;47(7):3421-6.

32. Zhang L, Yang Z, Chen Q, Li M, Zhu X, Wan D, et al. Mixed adenoendocrine carcinoma in the extrahepatic biliary tract: a case report and literature review. Oncol Lett. 2019:18(2):1585-96.

33. Brennan SM, Gregory DL, Stillie A, Herschtal A, Mac Manus M, Ball DL. Should extrapulmonary small cell cancer be managed like small cell lung cancer? Cancer. 2010;116(4):888-95.

34. Kim JH, Lee SH, Park J, Kim HY, Lee SI, Nam EM, et al. Extrapulmonary smallcell carcinoma: a single-institution experience. Jpn J Clin Oncol. 2004;34(5): 250-4.

\section{Publisher's Note}

Springer Nature remains neutral with regard to jurisdictional claims in published maps and institutional affiliations.

\section{Submit your manuscript to a SpringerOpen ${ }^{\circ}$ journal and benefit from:}

- Convenient online submission

- Rigorous peer review

- Open access: articles freely available online

- High visibility within the field

- Retaining the copyright to your article

Submit your next manuscript at $\boldsymbol{\nabla}$ springeropen.com 